Methodical Bases for the Study of the Adaptation of Children and Adolescents to the Conditions of Vital Functions]. Moscow ; 2006 : 238 p. (in Russian).

4. Kuchma V.R., Suhareva L.M., Rapoport I.K. et al. Organizatsiia meditsinskoi profilaktiki v obshcheobrazovatelnykh uchrezhdeniiakh [Organization of Medical Prophylaxis at General Education Institutions]. Moscow ; 2006 : 70 p. (in Russian).

5. Polka N.S. and Serheta I.V. Zhurnal NAMN Ukrainy. 2012 ; 18 (2) : 223-236 (in Ukrainian).

6. Polka N.S., Berdnyk O.V. Zhurnal NAMN Ukrainy. 2013 ; 19 (2) : 226-235 (in Ukrainian).

7. Sergeta I.V., Podrigalo L.V., Malachkova N.V. Oftalmo-gigienicheskie aspekty sovremennogo vizualnogo okruzheniia detei, podrostkov i molodezhi [Ophthalmohygienic Aspects of Modern Visual Surrounding of the Children, Adolescents and Young People].Vinnitsa : Dilo ; 2009 : 176 p. (in Russian).

8. Serdiuk A.M., Polka N.S. Sergeta I.V. Psikhogigiena detei i podrostkov, stradaiushchikh khronicheskimi somaticheskimi zabolevaniiami [Psychohygiene of Children and Adolescent

Suffering from Chronic Somatic Diseases].Vinnitsa : Nova Knyha ; 2012 : 336 p. (in Russian).

9. Ogniev V.A., Galicheva N.O., Sokol K.M., Usenko S.G., Fedak N.M., Rubinsky M.D. et al. Eksperymentalna I klinichna medytsyna. 2012 ; 1 : 164-169 (in Ukrainian).

10. Suharev A.G. Vestnik RAMN. 2006 ; 8 : 15-18 (in Russian).

11. Suharev A.G., Shelonina O.A. Nauchnye osnovy profilakticheskoi pediatrii [Scientific Bases of the Preventive Pediatrics]. In : Aktualnye problemy zdorovia detei i podrostkov i puti ikh resheniia [Actual Problems of the Children's and Adolescent's Health and the Ways of Their Solution]. Moscow ; 2012 : 411-412 (in Russian).

12. Chubarovskii V.V. Nekrasov M.A. Pogranichnye psikhicheskie rasstroistva i addiktivnye formy povedeniia u lits podrostkovogo i

yunosheskogo vozrasta [Borderline Mental Disorders and Addictive Forms of the Behavior in the Persons of Juvenile and Young Age]. Sergiev Posad (Russia) ; 2005 : 130 p.

(in Russian).

Надійшло до редакції 26.07.2016

\section{CLASSIFICATION OF RISK PERINATAL PERIOD OF LIFE THE NEWBORN}

Kovalenko O.S., Lep'okhina H.S., Azarkhov O.Yu., Zlepko S.M. КЛАСИФІКАЦИ РИЗИКІВ ПЕРИНАТАЛЬНОГ ПЕРІДУУ ЖИТТЯ НОВОНАРОДЖЕНИХ

\author{
1КОВАЛЕНКО О.С. \\ 2ЛЕПЬОХІНА Г.С. \\ ЗАЗАРХОВ О.Ю., 4 ЗЛЕПКО С.М. \\ ${ }^{1}$ Міжнародний науково- \\ навчальний центр інформацій-

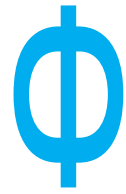
них технологій та систем НАН і МОН України, м. Київ

²Скадовська центральна районна лікарня

зПриазовський державний технічний університет

4Вінницький національний технічний університет

УДК $613.952: 004.9$

Ключові слова : перинатальні ризики, класифікація,

немовлята, охорона здоров'я, медична інформаційна система, профілактика, моніторинг, класифікаційна ознака. тини визначається багатьма факторами, серед яких важливе значення мають спосіб життя стан репродуктивного здоров'я батьків, соціальноекономічний рівень суспільства, біологічні та генетичні фактори, довкілля, організація і стан надання перинатальної медичної допомоги вагітним, дітям і матерям. Усі зазначені фактори впливають на перебіг перинатального періоду, стан здоров'я дитини у наступні роки життя.

Перинатальний період (починається 324 тижнів гестації, охоплює антенатальний, інтранатальний та ранній неонаталь- ормування здоров'я ди-

КЛАССИФИКАЦИЯ РИСКОВ ПЕРИНАТАЛЬНОГО ПЕРИОДА ЖИЗНИ НОВОРОЖДЕННОГО

1 Коваленко А.С., 2 Лепехина А.С., ${ }^{3}$ Азархов А.Ю., 4 ЗЗлепко С.М. ${ }^{1}$ Международный научно-учебный центр информационных технологий и систем НАН и МОН Украины, г. Киев; ${ }^{2}$ Скадовская центральная районная больница; ${ }^{3}$ Приазовский государственный технический университет; ${ }^{4}$ Винницкий национальный технический университет Цель работы - разработать классификацию рисков, сопровождающих мать и ребенка в перинатальном периоде жизни.

Материалы и методы: беременные, новорожденные и дети до 1 года жизни без какой-либо патологии. Новорожденные и дети до 1 года жизни с поражениями центральной нервной системы, проявляющимися в нарушении двигательных функций ребенка. Методы функциональной диагностики, прогнозирования состояния организма, математической статистики. Результаты. Предложенная классификация подтверждает необходимость комплексного взаимодействия медицинского персонала перинатальных центров и неопатологов для своевременного выявления факторов перинатальных рисков беременности и рисков новорожденных с одновременным определением причин, которые их обусловили. Именно такой подход свидетельствует о необходимости обеспечения современными медицинскими информационными системами и аппаратурой указанных центров и клиник. Обязательным элементом таких систем должны быть подсистемы поддержки принятия решений, которые на порядок повышают точность и достоверность диагностики и эффективность выбранной тактики лечения. Новым перспективным направлением снижения перинатальной патологии, реальной возможностью оптимизации формирования личности ребенка, лучшего психоэмоционального развития, снижения инвалидности с детства является перинатальная реабили тация плода и новорожденного. Привычный для врачей термин "реабилитация" касается ситуаций, когда действительно требуется восстановление утраченных функций. В то же время, когда речь идет о развитии плода и новорожденного, необходимо создать все условия для обеспечения физиологического развития, т.е. перинатальную реабилитацию. Выводы. Для медицинских учреждений это означает оперативное поступление данных к врачу, благодаря чему он получает возможность своевременного выявления и коррекции рисков, возникающих в перинатальном периоде и представляющих угрозу жизни ребенка и матери. Ключевые слова: перинатальные риски, классификация, новорожденные, здравоохранение, медицинская информационная система, профилактика, мониторинг, классификационный признак.

( Коваленко О.С., Лепьохіна Г.С., Азархов О.Ю., Злепко С.М. СТАТТЯ, 2016. 
CLASSIFICATION OF RISK PERINATAL PERIOD OF LIFE THE NEWBORN

1 Kovalenko O.S., ${ }^{2}$ Lep'okhina H.S., ${ }^{3}$ Azarkhov O. Yu., 4 Zlepko S.M.

1 International Research and Training Center for Information Technologies and Systems of the

National Academy of Sciences (NAS) of Ukraine and Ministry of Education and Science (MES) of Ukraine 2Skadovsk Central Region Hospital

3 Pryazovskyi State Technical University (PSTU)

${ }^{4}$ Vinnica national technical university

The purpose of work - to develop a classification of risks from the mother and child in the perinatal period of life.

Materials and methods. Pregnant women, infants and children under 1 year of age without any diseases. Infants and children under 1 year of age with lesions of the central nervous system, which manifests itself in violation of the motor function of the child. Methods of functional diagnostics, forecasting of the body, mathematical statistics.

Results. The classification confirms the need for complex interaction of medical personnel and perinatal centers neopatolohiv to detect risk factors of perinatal risk pregnancy and neonatal while determining the reasons that caused it. This approach demonstrates the need for providing modern med- ical equipment and systems niformatsiynymy these centers and clinics. An obligatory element of such systems should subsystems decision support rods in order improve the accuracy and reliability of the diagnosis and the effectiveness of the selected treatment.

Novыm perspektyvnыm direction Reduction perynatalnoy pathology, optimization realnoy vozmozhnostyu the formative personality of the child,

luchsheho psycho-emotional development, Reduction ynvalydnosty with childhood javljaetsja perinatalnaja Rehabilitation of the fetus and newborn. Pryvыchnыy for doctors term "Rehabilitation" kasaetsya situations, when utrachennыh Indeed Requires Restoration functions. At the same time, when Speech are talking about DEVELOPMENT fetus and newborn, it is necessary Create all terms to implement the physiological development, and a view ymeet perinatal Rehabilitation.

Conclusions. For medical institutions, this means rapid flow of information to the doctor, so that he is able to timely detection and correction of risks arising in the perinatal period and can endanger the life of the child and the mother.

Keywords: perinatal risk classification, newborns, health, medical information system, prevention, monitoring, classification attribute. ний періоди, або перші 168 годин життя дитини) становить лише 0,5-0,6\% від загальної тривалості життя людини. Водночас саме протягом перинатального періоду існує найвищий ризик формування патології, захворюваності і смертності порівняно з іншими періодами життя. Саме тому в усіх економічно розвинутих країнах світу приділяється значна увага розвитку і вдосконаленню системи перинатальної допомоги плоду, вагітній, новонародженому, породіллі [1].

Стан проблеми. Народження здорової дитини, фізіологічний розвиток плоду та новонародженого забезпечують $[1,2]$ планування вагітності, усвідомлене ставлення до народження дитини; антенатальне спостереження за розвитком плоду; визначення перинатального ризику вагітності 3 інтенсивним перинатальним доглядом у разі потреби; фетальний моніторинг; медико-генетичне консультування; своєчасне обстеження на провідні збудники перинатальних TORCH-інфекцій, які підвищують ризик формування перинатальної патології; психопрофілактична підготовка до пологів плоду і матері; фізіологічні пологи; викладання дитини на живіт матері одразу після пологів 3 наступним контактом «шкіра до шкіри» протягом не менше 60 хвилин, раннє прикладання дитини до грудей матері у перші 30 хвилин після народження; спільне перебування матерів і новонароджених у пологових будинках; грудне вигодовування немовлят.

Має перспективи розвитку перинатальна психологія як новий напрямок надання перинатальної допомоги з залученням широкого кола спеціалістів, а саме: перинатологів, акушерів-гінекологів, медичних (перинатальних) психологів, неонатологів, дитячих неврологів, педіатрів [4].

Новим перспективним напрямком зниження перинатальної патології, реальною можливістю оптимізації формування особистості дитини, кращого психоемоційного розвитку, зниження інвалідності з дитинства $€$ перинатальна реабілітація плоду і новонародженого. Звичніший для лікарів термін "реабілітація" стосується ситуацій, коли справді потрібне відновлення втрачених функцій. Водночас, коли йдеться про розвиток плоду і новонародженого, необхідно створити всі умови для забезпечення фізіологічного розвитку, що й має за мету «перинатальна габілітація» [1].

Таким чином, для зниження перинатальної патології, нео- натальної захворюваності і смертності необхідна регіоналізація перинатальної допомоги з наданням медичної допомоги вагітним і новонародженим у медичних лікувальнопрофілактичних закладах I, II, III рівнів залежно від ступеня перинатального ризику.

Невід'ємною складовою перинатальної медицини є висококваліфікована неонатальна допомога, що ґрунтується на аналізі перебігу вагітності й пологів, стану плоду протягом гестаційного періоду 3 урахуванням усіх факторів ризику, на прогнозуванні стану новонародженого з забезпеченням сучасними перинатальними технологіями надання медичної допомоги [1, 2].

Мета роботи - розробити класифікацію ризиків, що супроводжують мати і дитину у перинатальному періоді життя.

Результати та обговорення. На рисунку представлено запропоновану авторами класифікацію ризиків, які супроводжують мати і дитину від початку вагітності до досягнення дитиною віку не менше 1 року.

Особливістю даної класифікації $€$ те, що вона поєднала класифікації ризиків, які існують в окремих періодах вагітності та життя новона- 
Фактори пре-перинатального ризику

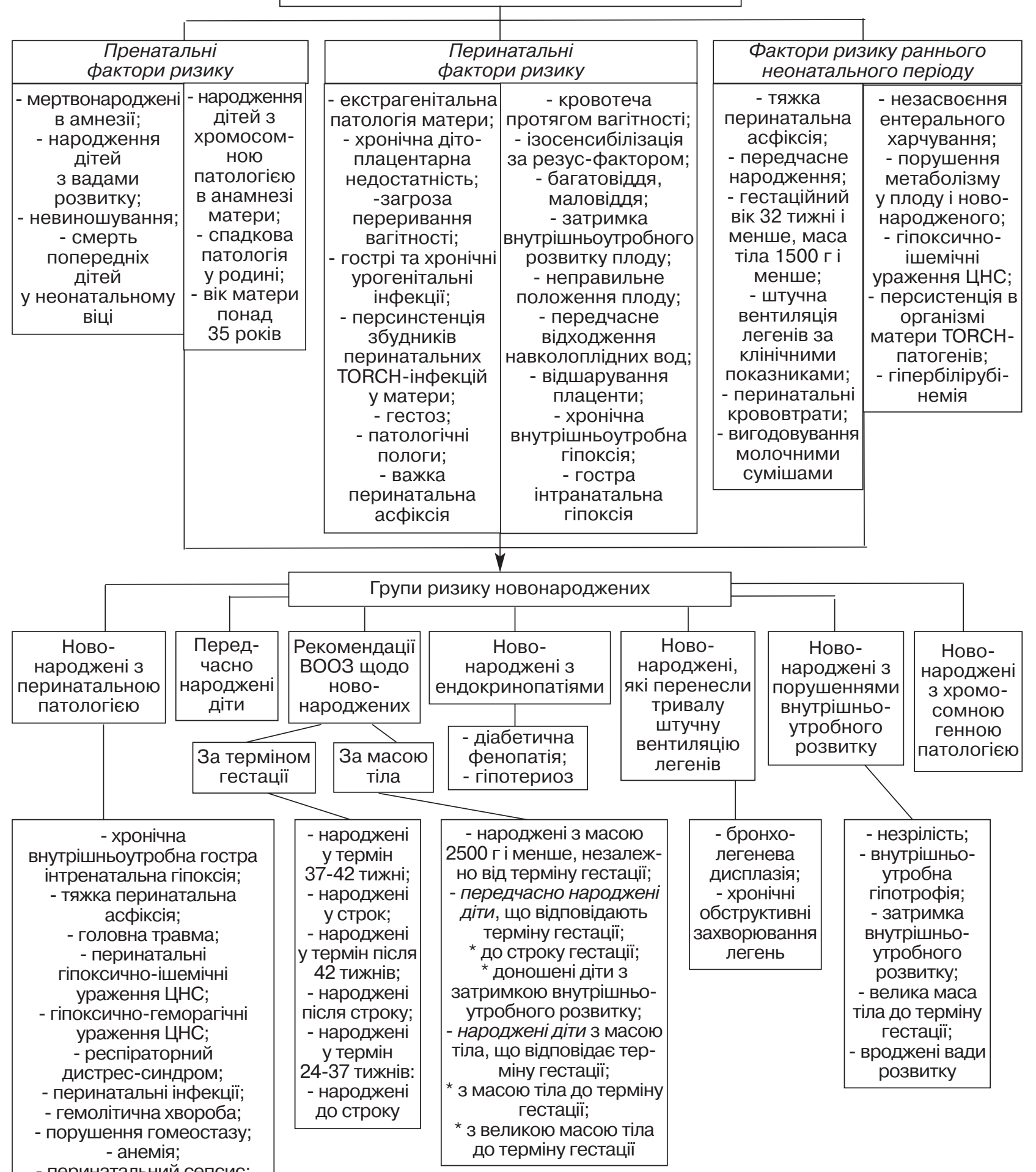

- перинатальний сепсис;

- імунодефіцитні стани;

- поліорганна недостатність;

- вроджені вади розвитку

\section{Класифікація ризиків матери і дитини}

роджених. Саме таке додаткові, такі як хромосомна поєднання показало: якщо не генна патологія, негативна приділяти належної уваги про- динаміка порушень внутрішфілактиці та усуненню ризиків нього розвитку, передчасне на етапі перинатального розвитку плоду, то існує велика ймовірність того, що новонароджена дитина не тільки успадкує ризики перинатального періоду, а й отримає нові,

\section{народження тощо.}

Запропонована класифікація підтверджує необхідність комплексної взаємодії акушерсько-гінекологічного медичного персоналу і неонато- логів для своєчасного визначення не лише самих факторів перинатальних ризиків вагітності і ризиків новонароджених, а й причин, що зумовили їх виникнення.

Саме така актуалізація проблеми своєчасного вивчення ризиків різного походження у матері, плода та новонарод- 
женого свідчить про необхідність забезпечення перинатальної медицини сучасними медичними інформаційними системами і технологіями, високофункціональним обладнанням для інтенсивного неонатального моніторингу та інтенсивної терапії. Передусім йдеться про системи кардіореспіраторного моніторингу: прилади для газоаналізу крови, у т.ч. і пульсоксиметрії; апаратуру для СРАР-терапії; комп'ютерні системи ранньої діагностики функціонального стану плоду; рентгенологічну, УЗ та томографічну апаратуру тощо.

Запропонована класифікація практично повністю відповідає новим парадигмам у сфері охорони здоров'я, які пропонує корпорація Microsoft [3], а саме: підвищення прозорості та ефективності роботи MIC і MIT шляхом застосування у них електронних історій хвороби, що сприяє постановці більш точних діагнозів, а пацієнтам надає можливість отримувати більш повну картину процесу лікування [3]; використання одного з функціональних принципів - довіри пацієнта - що забезпечує вдосконалення обробки історій хвороби і розвиток тенденції до ширшого використання MIC. При цьому IT-середовище, яке формується з використанням вищезазначених принципів і парадигм, практично гарантуватиме [3] оперативність, швидке реагування на зміну потреб і політики, можливість повторного використання компонентів, інтероперабельність і масштабованість, доступне програмне забезпечення, узгоджену компонентну модель процесу, узгоджені інтерфейси і стандарти доступу.

IT-середовище має не тільки відповідати вимогам лікувального закладу і споживачів медичних послуг, але й забезпечувати надійність, захищеність, готовність та інтероперабельність служб [3]:

- надійність - використання перевірених програмних продуктів і процесів управління;

- захищеність - впровадження засобів аутентифікації та ефективне застосування найкращих експлуатаційних процесів;
- готовність - застосування випробуваних і перевірених платформ і продуктів;

- корисність - відповідність вимогам;

- успішність - використання у багатьох секторах, державних і приватних;

- інтероперабельність висока віддача від інвестицій за рахунок інтеграції з наявними системами, які можна пристосувати для нових рішень і технологій.

Партнерський підхід корпорації Microsoft полягає у можливості проаналізувати наявне середовище, а потім працювати над створенням спільних наскрізних технологічних рішень. Структура, яка базується на партнерстві, дуже вигідна і може принести значні переваги у майбутньому, оскільки фактично це взаємодія трьох систем освіти, охорони здоров'я і соціального забезпечення [3]. Будуючи стабільні, довгострокові відносини з особами, які приймають рішення, лікарнями, страховими компаніями, фармацевтичною галуззю, видавництвами медичної літератури, професійними асоціаціями та урядом, можливо створити атмосферу довіри і партнерства.

\section{Висновки}

Таким чином, здатність технологій корпорації Microsoft та рішень її партнерів інтегрувати розрізнені системи без внесення змін до наявних програм означає нові можливості для тих, хто працює з медичною інформацією, а саме: отримання потрібної інформації у будь-який час.

Для медичних установ це означає надходження даних до місця лікування, завдяки чому лікарі можуть своєчасно переглянути останні лабораторні дані, отримати доступ до електронних історій хвороб і за допомогою портативних комп'ютерів виписати рецепти в електронному вигляді [3].

\section{ЛІТЕРАТУРА}

1. Перинатальные поражения центральной нервной системы // Информационная медицинская сеть НЕВРОНЕТ [Электронный ресурс]. Режим доступа: http://www. neuronet.ru/org/dknp/pep.html.

2. Факторы риска акушерской и перинатальной патологии [Электронный ресурс]. - Режим доступа: http://www.ginekolog.my1.ru/p ubl/akusherstvo/akusherskie_p atologii/faktory_riska_akusherskoj_i_perinatalnoj_patologii/21 -1-0-182.

3. Microsoft: Ваше здоровье - наша забота.

Усовершенствование здравоохранения с помощью новейших информационных технологий. Ч.1. // Клиническая информатика и телемедицина. - 2005. - № 1. - С. 1-13.

4. Перинатальная психология плода и новорожденного [Электронный ресурс]. Режим доступа:

http://www.detskydoctor.ru/doc /materialy-i-dokumenty-pogv/perinatalnaya-psihologiyaploda-i-novorozhdennogo.

\section{REFERENCES}

1. Perinatalnye

porazheniia tsentralnoi nervnoi sistemy [Perinatal Injuries of the Central Nervous System]. Available at: http://www.neuronet.ru/org/dknp/pep.html (in Russian).

2. Faktory riska akusherskoi i perinatalnoi patologii [Risk Factors of the Obstetric and Perinatal Pathology]. Available at : http://ginekolog. my1.ru/publ/akusherstvo/akush erskie_patologii/faktory_riska_a kusherskoj_i_perinatalnoj_patol ogii/21-1-0-182 (in Russian).

3. Microsoft Klinicheskaia informatika i telemeditsina. 2005 ; 1 : 1-13 (in Russian).

4. Perinatalnaia psikhologiia ploda i novorozhdennogo [Perinatal Psychology of the Fetus and Newborn].

Available at : http:// www.detskydoctor. Iru/doc/materialy-i-dokumentypo-gv/perinatalnaya-psihologiya-ploda-i-novorozhdennogo (in Russian).

Надійшло до редакції 21.06.2016 